\title{
Corrigendum
}

\section{BMR in a Brazilian adult probability sample: the Nutrition, Physical Activity and Health Survey - Corrigendum}

\author{
Luiz A Anjos, Vivian Wahrlich and Mauricio TL Vasconcellos
}

First published online 3 January 2013

doi:10.1017/S1368980012005381, published online by Cambridge University Press 3 January 2013

In this paper, the authors have inadvertently provided the correct predictive equation for BMR but in $\mathrm{kcal} / \mathrm{d}$ instead of $\mathrm{kJ} / \mathrm{d}$.

Therefore, in the last paragraph of the Results

instead of:

The generated equations are:

Males, BMR $(\mathrm{kJ} / \mathrm{d})=(9.99 \times \mathrm{BM})+(7.14 \times \mathrm{S})-(2.79 \times \mathrm{A})-450.5$

$\left(\mathrm{R}^{2}=0.87 ; \mathrm{SEE}=290.0 \mathrm{~kJ} / \mathrm{d}\right)$

and

Females, BMR $(\mathrm{kJ} / \mathrm{d})=(8.95 \times \mathrm{BM})+(8.87 \times \mathrm{S})-(0.70 \times \mathrm{A})-814.3$

$\left(\mathrm{R}^{2}=0.83 ; \mathrm{SEE}=254.5 \mathrm{~kJ} / \mathrm{d}\right)$

where SEE is the standard error of the estimate.

it should read:

The generated equations are:

Males, BMR $(\mathrm{kJ} / \mathrm{d})=(41.79 \times \mathrm{BM})+(29.86 \times \mathrm{S})-(11.69 \times \mathrm{A})-1884.93$

$\left(\mathrm{R}^{2}=0.87 ; \mathrm{SEE}=290.0 \mathrm{~kJ} / \mathrm{d}\right)$

and

Females, BMR $(\mathrm{kJ} / \mathrm{d})=(37.46 \times \mathrm{BM})+(37.13 \times \mathrm{S})-(2.92 \times \mathrm{A})-3407.09$

$\left(\mathrm{R}^{2}=0.83 ; \mathrm{SEE}=254.5 \mathrm{~kJ} / \mathrm{d}\right)$

where SEE is the standard error of the estimate.

The SEE in $\mathrm{kcal} / \mathrm{d}$ of the equations are 69.3 and $60.8 \mathrm{kcal} / \mathrm{d}$ for males and females, respectively.

\section{Reference}

Anjos LA, Wahrlich V and Vasconcellos MTL (2013) BMR in a Brazilian adult probability sample: the Nutrition, Physical Activity and Health Survey. Public Health Nutrition, published online 3 January 2013, doi:10.1017/S1368980012005381. 